Document downloaded from:

http://hdl.handle.net/10251/49863

This paper must be cited as:

Martí Calatayud, MC.; Cardoso Buzzi, D.; García Gabaldón, M.; Ortega Navarro, EM.; Bernardes, A.; Suarez Tenorio, JA.; Pérez Herranz, V. (2014). Sulfuric acid recovery from acid mine drainage by means of electrodialysis. Desalination. 343:120-127. doi:10.1016/j.desal.2013.11.031.

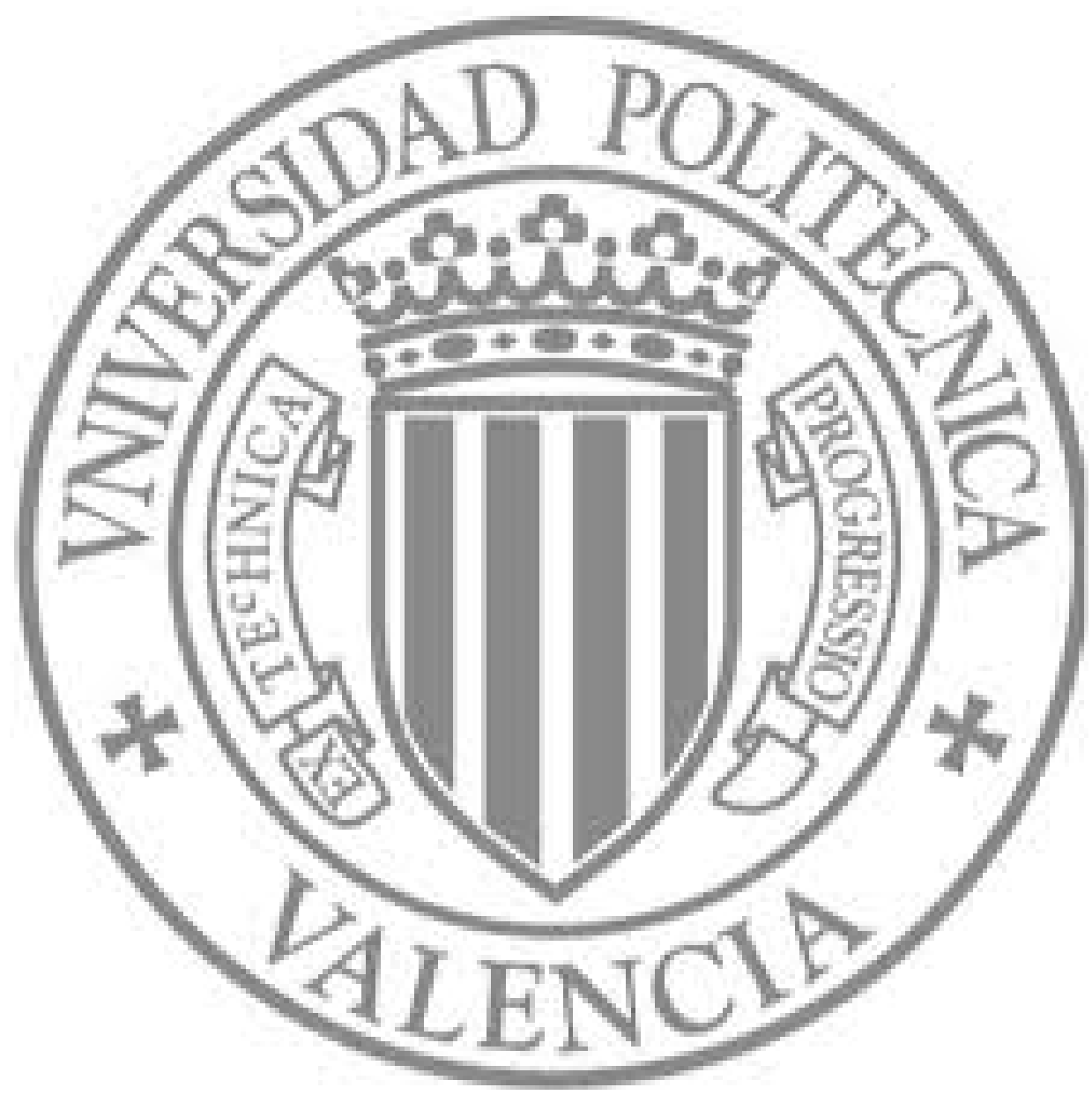

The final publication is available at

http://dx.doi.org/10.1016/j.desal.2013.11.031

Copyright Elsevier 


\title{
Sulfuric acid recovery from acid mine drainage by means of electrodialysis
}

\author{
M.C. Martí-Calatayud ${ }^{\mathrm{a}}$, D.C. Buzzi ${ }^{\mathrm{a}, \mathrm{b}, \mathrm{c}}$, M. García-Gabaldón ${ }^{\mathrm{a}}$, E. Ortega ${ }^{\mathrm{a}}$, \\ A. M. Bernardes ${ }^{c}$, J.A.S. Tenório ${ }^{\mathrm{b}}$, V. Pérez-Herranz ${ }^{\mathrm{a}, *}$
}

(a) IEC Group, Departamento de Ingeniería Química y Nuclear, Universitat Politècnica de València, Camí de Vera s/n, 46900 València, Spain. P.O. Box 22012, E-46071

(b) Department of Materials and Metallurgical Engineering, Universidade de São Paulo, Av. Prof. Mello Moraes, 2463, 05508-030, São Paulo, SP, Brazil

(c) Department of Materials Engineering, Universidade do Rio Grande do Sul, Av. Bento Gonçalves, 9500, 91509-900, Porto Alegre, RS, Brazil

* Corresponding author: Tel.: +34 963877632; Fax: +34 963867639.

E-mail addresses: vperez@iqn.upv.es (V.Pérez-Herranz), mamarc13@upvnet.upv.es (M.C. Martí-Calatayud), danicbuzzi@gmail.com (D.C. Buzzi)

Keywords: electrodialysis, acid mine drainage, ion exchange membranes, limiting current density, membrane fouling

\begin{abstract}
In the present work the recovery of sulfuric acid from acid mine drainage by means of 3-compartment electrodialysis (ED) is evaluated. An effective recovery of sulfuric acid free from Fe(III) species was obtained in the anodic compartment as a result of the coion exclusion mechanism in the membranes. The difference in the $\mathrm{pH}$ and $\mathrm{pSO}_{4}{ }^{2-}$ values between the membrane phase and the external electrolyte promotes the dissociation of complex species inside the membranes. This phenomenon impedes the transport of Fe(III) and sulfates in the form of complex ions toward the anodic and cathodic compartment, respectively. The current efficiency values of the anion-exchange membrane at different current densities were approximately constant with time. However, the increase in the recovery of acid decreases as the current increases. This result is explained by the shift in the equilibrium at the membrane/solution interface as more $\mathrm{SO}_{4}{ }^{2-}$ ions cross the anionic membrane and, by the enhancement of the
\end{abstract}


dissociation of water when the limiting current density is exceeded. The main limitation of the process is related to an abrupt increase in the cell voltage due to the formation of precipitates at the surface of the cation-exchange membrane.

\section{Introduction}

Mining industries represent an important source of metals, as well as an essential economic activity for the regions where they are located. However, the generation of acid mine drainage (AMD) entails important environmental problems due to the contamination of the surrounding watercourses. AMD is the result of the oxidation of sulfide minerals, mainly pyrite $\left(\mathrm{FeS}_{2}\right)$, when exposed to the combined action of water and oxygen. It contains considerable concentrations of $\mathrm{Fe}(\mathrm{III})$ and $\mathrm{Fe}(\mathrm{II})$ species, sulfates and other metals [1]. The hazards associated with these effluents stem from their acidic $\mathrm{pH}$ values and the toxicological effects of heavy metals on aquatic ecosystems [2, 3]. Among the different technologies that could be used to minimize the impact of AMD and make the water reuse in other activities possible, ED is selected because it is a clean technology entailing several advantages. ED does not imply the addition of chemicals, can be operated in continuous mode and allows obtaining profitable by-products $[4,5]$.

In particular, ED can be used to obtain a valuable product, such as sulfuric acid, from AMD. The sulfuric acid can be used as resource to offset the costs of treatment and make ED technologies more feasible than the typical treatment with limes [6]. However, in order to achieve this purpose, the treatment of AMD needs to be investigated previously. In ED systems, ion-exchange membranes are used to separate positively and negatively charged ions based on the fixed charges of the membranes. In consequence, the process of mass transfer through the membranes is accompanied by concentration polarization phenomena. The development of concentration gradients can limit the mass transfer through the membranes [7]. Moreover, concentration polarization not only affects the ionic transfer rates, but also the electrical resistance of membrane systems. This implies an important dependence of the current efficiency and the energy consumption of ED cells on the applied current. Additionally, other processes, such as $\mathrm{pH}$ changes, the electrode reactions or the presence of membrane fouling, can also converge during ED operations, thus affecting the process performance. Finally, the 
appropriate choice of the membranes is another important requirement for the treatment of industrial wastewaters. In order to improve the reliability of the process, the membranes should not degrade in contact with oxidizing or very acidic solutions and should be mechanically stable.

Different electro-membrane processes (e.g. bipolar ED, electro-electrodialysis or distinct ED configurations) have been effectively used to recover sulfuric acid from various industrial wastewaters, such as nuclear decontamination effluents or rinsing waters used in metal electrorefining operations [8-10]. However, in the particular case of iron-containing AMD solutions, the speciation of iron entails the presence of various ionic species of different charge and mobility [1], thus adding a further complexity in the interpretation of the mechanisms of ionic transport through ion-exchange membranes. In addition, the peculiar transport of protons and the phenomena related to the proton leakage through anion-exchange membranes (AEMs) are other characteristics which have to be considered when recovering acids by means of electromembrane processes. All these factors affect the performance of the ED operations and determine to a great extent the purity of the final products.

Therefore, the main objective of this study is to investigate the transport processes determining the mass transfer rates and energetic efficiency of ED processes used to treat AMD solutions. For this purpose, ion-exchange membranes featured as chemically and mechanically resistant are employed at different current densities. In order to evaluate the viability of the recovery of sulfuric acid from iron-containing solutions, we put special emphasis on the formation of different ionic species. This approach will allow us to interpret the different phenomena involved in the mass transport through the membranes. Finally, the main benefits and limitations of this technology are identified by evaluating the effect of the applied current density on the mass transfer rates and energy-related indicators. 


\section{Experimental}

\subsection{Membranes and reagents}

The ion-exchange membranes used in the present study are heterogeneous HDX membranes (provided by Hidrodex ${ }^{\circledR}$ ). The AEM (HDX 200) contains quaternary amine groups attached to the membrane matrix. The cation-exchange membrane (CEM, HDX 100 ) is charged with sulfonic acid groups and has a similar morphology to that of HDX 200. Both membranes have remarkably high ion-exchange capacities, which are 1.8 and $2.0 \mathrm{mmol} \cdot \mathrm{gr}^{-1}$ for the AEM and the CEM, respectively [11]. The structure of both membranes is reinforced with two nylon fabrics with the function of increasing their mechanical stability. Prior to conducting the experiments, the membranes were equilibrated in the solutions to be used subsequently during at least $24 \mathrm{~h}$.

The composition of AMD varies substantially depending on the source from which samples are collected. In a previous study, the composition of different AMD solutions obtained from a carboniferous area in Criciúma/SC (Brazil) was elucidated [11]. The AMD solution with the highest concentration of sulfates was selected as a basis for the present investigation, since the principal aim of this work is the recovery of sulfuric acid from AMD. Synthetic solutions with a composition approximate to that of the original AMD solution were prepared by mixing $0.02 \mathrm{M} \mathrm{Fe}_{2}\left(\mathrm{SO}_{4}\right)_{3}$ and $0.01 \mathrm{M} \mathrm{Na}_{2} \mathrm{SO}_{4}$ (Panreac ${ }^{\circledR}$ ). The solution to be concentrated in the anodic compartment was prepared from $\mathrm{H}_{2} \mathrm{SO}_{4}$ (J.T. Baker). Distilled water was used to prepare the synthetic solutions. The content of the most concentrated species in the original AMD source is summarized in Table 1, together with the concentrations and $\mathrm{pH}$ value of the synthetic solutions.

\subsection{ED experiments}

The principle of the process proposed in this work is shown in Fig. 1. The pilot plant used in the experiments consists of an ED cell divided in three compartments with recirculation. At the beginning of the experiments, the feed of the central and the cathodic compartment simulates the composition of AMD (0.02 $\mathrm{M} \mathrm{Fe}_{2}\left(\mathrm{SO}_{4}\right)_{3}$ and $0.01 \mathrm{M} \mathrm{Na}_{2} \mathrm{SO}_{4}$ ), and the anodic reservoir contains $0.07 \mathrm{M} \mathrm{H}_{2} \mathrm{SO}_{4}$. The streams are pumped through the ED cell with a flow rate of $50 \mathrm{~L} \cdot \mathrm{h}^{-1}$. Under the application of a 
constant current, the AEM, placed between the anodic and the central compartment, facilitates the transport of $\mathrm{SO}_{4}{ }^{2-}$ ions toward the anode. In addition, $\mathrm{H}^{+}$ions are generated at the anode surface as a product of the water oxidation reaction. As a result, the concentration of sulfuric acid increases in this compartment. Simultaneously, the central solution becomes depleted of positively charged ions that are transferred through the CEM. The ratio between the volume of the central and the side reservoirs was set to $4: 1$, so that the increase in the cell voltage could be limited and the passage of $\mathrm{SO}_{4}{ }^{2-}$ ions to the anodic compartment could be ensured during the 10 hours of operation. The effective area of the membranes and the electrodes was of $100 \mathrm{~cm}^{2}$. A power supply was used to impose the current between anode and cathode. The anode consisted of a mixed metal oxide $\left(\mathrm{RuO}_{2} / \mathrm{IrO}_{2}\right.$ : 0.70/0.30) coated sheet of titanium (Magneto special anodes B.V., The Netherlands) and a sheet of AISI 304 stainless steel was used as cathode. The electrode reactions are given by Eqs. (1)-(5):

Cathode:

$$
\begin{gathered}
2 \mathrm{H}_{2} \mathrm{O}+2 e^{-} \rightarrow \mathrm{H}_{2} \uparrow+2 \mathrm{OH}^{-} \\
\mathrm{Fe}^{3+}+1 e^{-} \rightarrow \mathrm{Fe}^{2+} \\
\mathrm{Fe}^{2+}+2 e^{-} \rightarrow \mathrm{Fe}^{0} \\
\mathrm{Fe}^{3+}+3 e^{-} \rightarrow \mathrm{Fe}^{0}
\end{gathered}
$$

Anode:

$$
2 \mathrm{H}_{2} \mathrm{O} \rightarrow \mathrm{O}_{2} \uparrow+4 \mathrm{H}^{+}+4 e^{-}
$$

The concentration of sulfates in the different compartments was measured by conductometric titration using barium acetate as titrant. The concentration of total iron was also measured by atomic absorption spectrometry (Perkin Elmer, Model Analyst100) with a lamp current of $5 \mathrm{~mA}$ and a wave length of $248.3 \mathrm{~nm}$. 


\section{Results and discussion}

\subsection{Speciation of mixtures of ferric and sodium sulfate}

The mixture used to conduct the ED galvanostatic experiments, composed of $0.02 \mathrm{M}$ $\mathrm{Fe}_{2}\left(\mathrm{SO}_{4}\right)_{3}$ and $0.01 \mathrm{M} \mathrm{Na}_{2} \mathrm{SO}_{4}$, can give rise to the formation of several ionic species in solution. The initial concentration of each species and the speciation diagrams of this solution were hence calculated in order to take into account the transport of different ionic species through the membranes. The formation of complex species of $\mathrm{Fe}^{3+}$ with $\mathrm{OH}^{-}$ions is described by Eqs. (6)-(9) [12]:

$$
\begin{array}{lc}
\mathrm{Fe}^{3+}+\mathrm{OH}^{-} \rightleftarrows \mathrm{FeOH}^{2+} & \beta_{1}=10^{11.81} \\
\mathrm{Fe}^{3+}+2 \mathrm{OH}^{-} \rightleftarrows \mathrm{Fe}(\mathrm{OH})_{2}{ }^{+} & \beta_{2}=10^{22.3} \\
\mathrm{Fe}^{3+}+3 \mathrm{OH}^{-} \rightleftarrows \mathrm{Fe}(\mathrm{OH})_{3} & \beta_{3}=10^{30} \\
\mathrm{Fe}^{3+}+4 \mathrm{OH}^{-} \rightleftarrows \mathrm{Fe}(\mathrm{OH})_{4}^{-} & \beta_{4}=10^{34.4}
\end{array}
$$

The complexation of $\mathrm{Fe}^{3+}$ with $\mathrm{SO}_{4}{ }^{2-}$ ions as ligands was also taken into account with the Eqs. (10) and (11):

$$
\begin{array}{ll}
\mathrm{Fe}^{3+}+\mathrm{SO}_{4}{ }^{2-} \rightleftarrows \mathrm{FeSO}_{4}{ }^{+} & \beta_{1}^{\prime}=10^{4.04} \\
\mathrm{Fe}^{3+}+2 \mathrm{SO}_{4}{ }^{2-} \rightleftarrows \mathrm{Fe}\left(\mathrm{SO}_{4}\right)_{2}{ }^{-} & \beta_{2}^{\prime}=10^{5.38}
\end{array}
$$

Moreover, the formation of precipitates was also considered:

$$
\mathrm{Fe}^{3+}+3 \mathrm{OH}^{-} \rightleftarrows \mathrm{Fe}(\mathrm{OH})_{3}(\mathrm{~s}) \quad \mathrm{K}_{\mathrm{s}}\left(\mathrm{Fe}(\mathrm{OH})_{3}\right)=10^{-38.8}
$$

In the case of $\mathrm{Na}^{+}$ions, the following equilibria were considered:

$$
\begin{array}{ll}
\mathrm{Na}^{+}+\mathrm{OH}^{-} \rightleftarrows \mathrm{NaOH} & \beta_{1}=10^{-0.2} \\
\mathrm{Na}^{+}+\mathrm{SO}_{4}{ }^{2-} \rightleftarrows \mathrm{NaSO}_{4}^{-} & \beta_{1}^{\prime}=10^{0.7}
\end{array}
$$

Besides, $\mathrm{SO}_{4}{ }^{2-}$ ions can also participate in hydrolysis reactions, which are given by Eq. (15) and (16): 


$$
\begin{array}{lr}
\mathrm{H}_{2} \mathrm{SO}_{4} \rightleftarrows \mathrm{HSO}_{4}{ }^{-}+\mathrm{H}^{+} & \mathrm{K}_{\mathrm{H} 1}=10^{3} \\
\mathrm{HSO}_{4}{ }^{-} \rightleftarrows \mathrm{SO}_{4}{ }^{2-}+\mathrm{H}^{+} & \mathrm{K}_{\mathrm{H} 2}=10^{-1.99}
\end{array}
$$

The stability constants of the reactions presented above are defined as follows:

$$
\begin{gathered}
\beta_{i}=\frac{\left[\mathrm{M}(\mathrm{OH})_{i}^{n-i}\right]}{\left[\mathrm{M}^{+n}\right] \times\left[\mathrm{OH}^{-}\right]^{i}} \\
\beta_{i}^{\prime}=\frac{\left[M\left(\mathrm{SO}_{4}\right)_{i}^{n-2 i}\right]}{\left[M^{+n}\right] \times\left[\mathrm{SO}_{4}^{2-}\right]^{i}} \\
K_{S}=\left[M^{+n}\right] \times\left[\mathrm{OH}^{-}\right]^{n} \\
K_{H i}=\frac{\left\lfloor H^{+}\right] \times\left\lfloor H_{2-i} S O_{4}^{-i}\right]}{\left[\mathrm{H}_{3-i} \mathrm{SO}_{4}^{1-i}\right]}
\end{gathered}
$$

In order to calculate the concentrations of each species, the system of equations formed by the mass balance of sulfates, $\mathrm{Fe}(\mathrm{III})$ species and $\mathrm{Na}$ (I) species (Eqs. (21)-(23)) together with the proton balance given by Eq. (24) was solved:

$$
\begin{aligned}
& {[\mathrm{Fe}(\mathrm{III})]_{0}=\left[\mathrm{Fe}^{3+}\right]+\left[\mathrm{FeOH}^{2+}\right]+\left[\mathrm{Fe}(\mathrm{OH})_{2}{ }^{+}\right]+\left[\mathrm{Fe}(\mathrm{OH})_{3}\right]+\left[\mathrm{Fe}(\mathrm{OH})_{4}{ }^{-}\right]+\left[\mathrm{FeSO}_{4}{ }^{+}\right]+} \\
& {\left[\mathrm{Fe}\left(\mathrm{SO}_{4}\right)_{2}{ }^{-}\right]} \\
& {[\mathrm{Na}(\mathrm{I})]_{0}=\left[\mathrm{Na}^{+}\right]+[\mathrm{NaOH}]+\left[\mathrm{NaSO}_{4}^{-}\right]} \\
& {\left[\mathrm{SO}_{4}{ }^{2-}\right]_{0}=\left[\mathrm{SO}_{4}{ }^{2-}\right]+\left[\mathrm{FeSO}_{4}^{+}\right]+2\left[\mathrm{Fe}\left(\mathrm{SO}_{4}\right)_{2}^{-}\right]+\left[\mathrm{HSO}_{4}{ }^{-}\right]+\left[\mathrm{H}_{2} \mathrm{SO}_{4}\right]+\left[\mathrm{NaSO}_{4}{ }^{-}\right]} \\
& {\left[\mathrm{H}^{+}\right]=\left[\mathrm{OH}^{-}\right]+\left[\mathrm{FeOH}^{2+}\right]+2\left[\mathrm{Fe}(\mathrm{OH})_{2}{ }^{+}\right]+3\left[\mathrm{Fe}(\mathrm{OH})_{3}\right]+4\left[\mathrm{Fe}(\mathrm{OH})_{4}{ }^{-}\right]+[\mathrm{NaOH}]-} \\
& {\left[\mathrm{HSO}_{4}^{-}\right]-2\left[\mathrm{H}_{2} \mathrm{SO}_{4}\right]}
\end{aligned}
$$

According to the previously defined reactions and balances, the concentration of each ionic species is presented in Table 2. The principal cationic species in equilibrium conditions are $\mathrm{FeSO}_{4}{ }^{+}$and $\mathrm{Na}^{+}$ions, while $\mathrm{HSO}_{4}{ }^{-}, \mathrm{SO}_{4}{ }^{2-}$ and $\mathrm{Fe}\left(\mathrm{SO}_{4}\right)_{2}{ }^{-}$are the most concentrated anionic species. 
Moreover, in ED systems the initial equilibrium conditions can vary due to changes originated by the membrane selectivity or due to variations in the $\mathrm{pH}$ values, especially in the diffusion boundary layers formed at the membrane/solution interface and in the interstitial membrane solution. In order to take into account these variations, the speciation diagram of $\mathrm{SO}_{4}{ }^{2-}$ species as a function of $\mathrm{pH}$ was obtained. For this purpose, the fraction of sulfates provided by each species present in the solution $\left(\alpha_{i}\right)$ was calculated and is represented as a function of $\mathrm{pH}$ in Fig. 2. The displacement of the initial conditions toward lower $\mathrm{pH}$ values leads to an increase in the relative concentration of $\mathrm{HSO}_{4}{ }^{-}$, while the evolution of free $\mathrm{SO}_{4}{ }^{2-}$ ions and $\mathrm{Fe}\left(\mathrm{SO}_{4}\right)_{2}{ }^{-}$ions is the opposite. When the $\mathrm{pH}$ exceeds values higher than 2.5 the concentration of $\mathrm{SO}_{4}{ }^{2-}$ ions becomes predominant.

Following an analogous procedure, the fraction of $\mathrm{Fe}(\mathrm{III})$ species was also calculated and the speciation diagram of Fe(III) species as a function of $\mathrm{pH}$ is shown in Fig. 3(a). At $\mathrm{pH}$ values around the initial of the solutions (1.68), the concentration of $\mathrm{FeSO}_{4}{ }^{+}$ions is considerably higher than that of other cations, such as $\mathrm{Fe}^{3+}$ ions. Moreover, it is to be noted that the speciation of ionic species changes at a $\mathrm{pH}$ of 2.3 , which is consequence of the formation of precipitates of iron. Likewise, the speciation diagram of Fe(III) species as a function of the $\mathrm{pSO}_{4}{ }^{2-}$ is presented in Fig. 3(b), showing a general predominance of $\mathrm{FeSO}_{4}{ }^{+}$ions at $\mathrm{pSO}_{4}{ }^{2-}$ values close to the initial one.

\subsection{Recovery of sulfuric acid}

In order to evaluate the recovery of sulfuric acid in the anodic compartment of the ED cell, three galvanostatic experiments were carried out at the current densities of 5, 10 and $15 \mathrm{~mA} \cdot \mathrm{cm}^{-2}$. The limiting current densities ( $i_{\text {lim }}$ ) of both membranes were determined previously using an experimental setup described in a preceding study [13]. The $\mathrm{i}_{\text {lim }}$ defines the current at which the behavior of the membrane system changes from a quasi-ohmic pattern to a behavior in which the ionic transfer is limited by diffusion. The $\mathrm{i}_{\text {lim }}$ values were 15.58 and $6.80 \mathrm{~mA} \cdot \mathrm{cm}^{-2}$ for the CEM and AEM, respectively. Therefore, depending on each galvanostatic experiment the applied current density can correspond to the under- or overlimiting range of currents for each membrane. 
The experiments lasted for $10 \mathrm{~h}$ and the concentration of $\mathrm{SO}_{4}{ }^{2-}$ and $\mathrm{H}^{+}$ions was measured in the central and the anodic compartments. Fig. 4 shows the evolution with time of the concentration of sulfates in the anodic and central compartments for the three current densities tested. The concentration of sulfates in the anodic compartment increased with time for all the currents, independently of the range of applied current. Moreover, the transport of $\mathrm{SO}_{4}{ }^{2-}$ ions through the AEM increased with current. For the highest current value, the concentration of sulfates at the end of the experiment reached 3.5 times the initial concentration. On the other hand, the concentration of sulfates decreased in the central compartment, as it was expected. However, this decrease was small as a consequence of the greater volume of solution in the central reservoir in comparison with that of the anodic tank.

According to the data shown in Table 2 and the speciation diagram of Fig. 2, $\mathrm{HSO}_{4}^{-}$, $\mathrm{Fe}\left(\mathrm{SO}_{4}\right)_{2}{ }^{-}$and $\mathrm{SO}_{4}{ }^{2-}$ ions should be the species transported through the AEM. In order to quantify the contribution of the transport of $\mathrm{Fe}\left(\mathrm{SO}_{4}\right)_{2}{ }^{-}$ions, the concentration of iron in the anodic compartment was measured at the end of the experiments. The concentration of Fe(III) resulted negligible after the $10 \mathrm{~h}$ of operation for each applied current density, which was unexpected in view of the equilibrium concentrations of Table 2. This important finding has a beneficial impact on the recovery of sulfuric acid, since the presence of impurities in the final product is thus avoided.

In order to elucidate the mechanism responsible for the rejection of Fe(III) species by the AEM, the role of the Donnan exclusion mechanism of co-ions in the membrane phase has to be considered. The presence of fixed charges in the membrane matrix excludes those ions with the same charge sign from entering inside the membrane internal solution. In the case of an AEM, the exclusion of $\mathrm{H}^{+}$ions from the membrane phase increases the equivalent fraction of $\mathrm{OH}^{-}$ions, thus leading to $\mathrm{pH}$ values in the AEM higher than in the surrounding electrolyte [14]. This phenomenon can have an important influence on the mass transport through ion-exchange membranes, especially in the case of weak electrolytes, as reported by Pismenskaya et al. in studies dealing with the transport of salts of carbonic and phosphoric acids through AEMs [14-16].

In the present case, the increased $\mathrm{pH}$ values in the membrane phase originate the displacement of the equilibrium conditions from those of the bulk electrolyte. This 
phenomenon can be illustrated by considering a shift in the $\mathrm{pH}$ of the speciation diagram of Fig. 2 toward higher $\mathrm{pH}$ values. Under these circumstances, the reaction (11) is displaced toward the formation of $\mathrm{Fe}^{3+}$ and $\mathrm{SO}_{4}{ }^{2-}$ ions. Once occurred the dissociation of $\mathrm{Fe}\left(\mathrm{SO}_{4}\right)_{2}{ }^{-}$ions, the resulting $\mathrm{SO}_{4}{ }^{2-}$ ions may cross the membrane toward the anodic compartment, whereas $\mathrm{Fe}^{3+}$ ions migrate back to the central compartment owing to the influence of the imposed electric field.

Similar to the process occurring with the $\mathrm{Fe}\left(\mathrm{SO}_{4}\right)_{2}{ }^{-}$ions, the $\mathrm{HSO}_{4}{ }^{-}$ions may dissociate when reaching the membrane phase, hence supplying $\mathrm{SO}_{4}{ }^{2-}$ and $\mathrm{H}^{+}$ions to the anodic and the central compartment, respectively. Both processes are schematically represented in Fig. 5, where the difference between the $\mathrm{pH}$ of the membrane and the outer solution is indicated. In agreement to our results, other authors investigated the transport of sulfuric acid through AEMs and found out that only the $\mathrm{SO}_{4}{ }^{2-}$ ions crossed the membranes $[17,18]$. The same conclusion was reached in a recent study, where the predominant role of the gel phase of AEMs with high ion-exchange capacities was suggested to be the reason for the stronger Donnan exclusion of co-ions causing the dissociation of $\mathrm{HSO}_{4}{ }^{-}$ions [19]. However, in contrast to the advantages of the rejection of $\mathrm{Fe}(\mathrm{III})$ species by the AEM, the dissociation of $\mathrm{HSO}_{4}{ }^{-}$ions in the membrane phase reduces the efficiency of the recovery of sulfuric acid. First, the transport of each free $\mathrm{SO}_{4}{ }^{2-}$ ion through the AEM implies the transfer of two equivalents instead of one, which would be the case for $\mathrm{HSO}_{4}{ }^{-}$ions. In addition, the transport of $\mathrm{HSO}_{4}{ }^{-}$ions through the AEM would contribute to a further increase in the acidity of the anodic compartment.

Regarding the increase in the concentration of protons in the anodic compartment, the acidity was measured at the conclusion of the experiments by means of titration against $0.5 \mathrm{M} \mathrm{NaOH}$ using phenolphthalein as indicator. In addition, the evolution of $\mathrm{pH}$ with time was also measured in the different compartments. The final acidity, presented in Fig. 6(a), shows a progressive increase with the current density, as occurs with the concentration of sulfates. The concentrating ratio of sulfuric acid was calculated from the quotient between the initial and final acidity values, resulting in 2.64, 3.36 and 4.00 for 5,10 and $15 \mathrm{~mA} \cdot \mathrm{cm}^{-2}$, respectively. Therefore, the increment in the acidity for the same current increase diminishes in the case of $10 \mathrm{~mA} \cdot \mathrm{cm}^{-2}$ and $15 \mathrm{~mA} \cdot \mathrm{cm}^{-2}$. If we assume that the efficiencies in the anodic reaction are constant for all the currents, the following phenomena could explain these differences: 
(i) The water splitting process can be enhanced when surpassing the $i_{\text {lim }}$ of the membranes, especially in the case of AEMs [20]. The $\mathrm{OH}^{-}$ions generated would be transferred to the anodic compartment, thus partially compensating the increase in acidity associated with the water oxidation reaction.

(ii) The transport mechanism of $\mathrm{SO}_{4}{ }^{2-}$ ions through the AEM involves the hydrolysis of each free $\mathrm{SO}_{4}{ }^{2-}$ ion reaching the anodic compartment in order to give a $\mathrm{HSO}_{4}{ }^{-}$ion. This reaction is favored by the $\mathrm{pH}$ change from the membrane phase to the more acidic conditions of the anodic chamber $(\mathrm{pH}<$ 1).

(iii) The proton leakage through the membrane would also imply a transfer of $\mathrm{H}^{+}$ ions from the anodic to the central compartment. This phenomenon is based on the exchange of $\mathrm{H}^{+}$ions between successive water molecules, either by a proton hopping mechanism (Grotthus mechanism) or by a succession of molecular rotations of the $\mathrm{H}_{2} \mathrm{O}$ dipoles (Bjerrum fault mechanism) [21].

Further research would be necessary to discern which of those phenomena is the most relevant. However, the enhancement of the water splitting reaction when the current exceeds the $i_{\text {lim }}$ of the AEM seems a consistent reason for the reduced increments in acidity observed for 10 and $15 \mathrm{~mA} \cdot \mathrm{cm}^{-2}$. Moreover, the rate of catalytic dissociation of water in ion-exchange membranes is expected to increase with current and is favored by the presence of weak electrolytes, as has been indicated in previous studies [22].

The increased flux of $\mathrm{SO}_{4}{ }^{2-}$ ions through the membrane with increasing current densities is also consistent with the limited increase in the concentrating ratios of sulfuric acid obtained for 10 and $15 \mathrm{~mA} \cdot \mathrm{cm}^{-2}$, since the $\mathrm{SO}_{4}{ }^{2-}$ ions reaching the anodic chamber consume protons to form $\mathrm{HSO}_{4}{ }^{-}$ions. In this regard, Lorrain et al. observed that the proton leakage through AEMs in the case of $\mathrm{H}_{2} \mathrm{SO}_{4}$ solutions was significantly higher than for $\mathrm{HCl}$ solutions [17]. Considering the different $\mathrm{pH}$ in each compartment with respect to that of the membrane phase, this effect may be caused by the readjustment in the equilibrium conditions at both membrane/solution interfaces as $\mathrm{SO}_{4}{ }^{2-}$ ions are transported through the membrane. Therefore, the apparent higher proton leakage observed with $\mathrm{H}_{2} \mathrm{SO}_{4}$ solutions could be associated with the involvement of $\mathrm{H}^{+}$ions in opposite hydrolysis reactions at each side of the membrane, rather than with a true increase in the amount of $\mathrm{H}^{+}$ions crossing the membrane. Specifically, each $\mathrm{HSO}_{4}{ }^{-}$ion 
dissociated in the membrane phase releases one proton toward the diluting compartment (direct sense of the reaction of Eq.(16)). On the other hand, as $\mathrm{SO}_{4}{ }^{2-}$ ions cross the membrane and reach the anodic membrane/solution interface, the reverse reaction of Eq.(16) is favored due to the $\mathrm{pH}$ difference, thus consuming free $\mathrm{H}^{+}$ions from the anodic compartment.

Finally, the effect of current density on the magnitude of the proton leakage through the membrane is not as clear as with the other two phenomena. This process is associated with the water content inside the internal pore solution of the AEM. With reference to this effect, Huang et al. observed a decrease in the current efficiency for the recovery of sulfuric acid with decreasing the applied current and attributed this result to the greater water transport occurring at low current densities [23].

Regarding the $\mathrm{pH}$ values, Fig. 6(b) shows the evolution of $\mathrm{pH}$ with time in the three compartments for the experimental conditions of $10 \mathrm{~mA} \cdot \mathrm{cm}^{-2}$. A significant decrease in the $\mathrm{pH}$ of the anolyte occurred as a consequence of the electrode reaction, which contributes to increase the concentration of sulfuric acid. In the central and the cathodic compartment, the $\mathrm{pH}$ values remained almost constant. In the case of the cathodic reservoir, the moderate variations in $\mathrm{pH}$ could be explained as a consequence of the compensation between the $\mathrm{H}^{+}$ions transported through the $\mathrm{CEM}$ and the $\mathrm{OH}^{-}$ions generated at the cathode surface as a product of the reduction of water (Eq. (1)). The slight variations of $\mathrm{pH}$ in the central compartment are justified by the greater volume of this reservoir. The $\mathrm{pH}$ results obtained for the other current densities (not shown) are analogous.

\subsection{Transport of iron through the CEM}

The concentration of total iron was measured in the central and cathodic compartments in order to analyze the transport of Fe(III) through the CEM and elucidate its influence on the overall performance of the ED cell. Fig. 7 shows the evolution with time of the concentration of iron in the cathodic compartment. It must be noted, that the evolution of $\mathrm{Fe}(\mathrm{III})$ in the central compartment (not shown) was similar to that of $\mathrm{SO}_{4}{ }^{2-}$ ions, with a very slow decrease in the concentration due to the greater volume of the central reservoir. The final concentrations of Fe(III) in the central compartment were 0.028, 
0.022 and $0.022 \mathrm{M}$ for 5,10 and $15 \mathrm{~mA} \cdot \mathrm{cm}^{-2}$, respectively. In the cathodic compartment, the concentration of iron shows two different trends for all the applied currents. At the beginning of the experiments the concentration of iron increased in the cathodic compartment due to the ionic transport occurring through the CEM. However, after a certain time the concentration of iron diminished and reached a final concentration lower than the initial one. This decrease was more pronounced with increasing current densities.

The changing trend observed in the evolution of iron with time can be explained as a result of the difference between the rate of transport of Fe(III) through the CEM and the rate of reduction of iron at the surface of the cathode (Eqs. (3) and (4)). It seems that the efficiency of the reduction of iron is low at the beginning of the experiments, which is usually related to the activation of the electrodes [24]. Once the surface of the electrodes is active for the deposition of iron, this reaction occurs faster than the transport of $\mathrm{Fe}(\mathrm{III})$ through the membrane, thus leading to a decrease in the concentration of iron with time. This difference may be incremented by the competitive transport of $\mathrm{Na}^{+}$ions through the CEM. In addition, we can observe that the time delay related to the activation of the electrode diminishes as the applied current increases.

It should be noted that the concentration of iron in the central compartment at the end of the experiments was the same for 10 and $15 \mathrm{~mA} \cdot \mathrm{cm}^{-2}$. This result is related to the formation of $\mathrm{Fe}(\mathrm{OH})_{3}$ precipitates at the anodic surface of the CEM as a result of surpassing the $\mathrm{i}_{\lim }$ of the CEM during the course of the experiment conducted at 15 $\mathrm{mA} \cdot \mathrm{cm}^{-2}$. It is known that the $i_{\text {lim }}$ value of an ion-exchange membrane is directly proportional to the concentration of counter-ions in the electrolyte [25]. Therefore, as the concentration in the depleting compartment decreases, the $\mathrm{i}_{\text {lim }}$ of the CEM could diminish up to the point of reaching the same value as the applied current [24]. At this moment, the formation of $\mathrm{Fe}(\mathrm{OH})_{3}$ precipitates at the anodic surface of a cationic membrane can be enhanced, thus acting as a blocking mechanism for the ionic transfer through the membrane [26,27]. The precipitates formed under the conditions of 15 $\mathrm{mA} \cdot \mathrm{cm}^{-2}$ were observed at the anodic side of the CEM at the end of the experiments. Other consequences of the fouling of the membranes are related to the energy consumption of the ED cell, which are discussed below in section 3.4. 
Finally, the concentration of sulfates in the cathodic compartment was measured at the end of the experiments. The measurements revealed that the concentration of sulfates remained unchanged with time. Analogously as occurred with the AEM, the Donnan co-ion exclusion in the membrane phase seems to affect the ionic species transported through the CEM. However, in this case the co-ions excluded from the membrane phase should be the $\mathrm{OH}^{-}$and $\mathrm{SO}_{4}{ }^{2-}$ ions. In consequence, inside the membrane phase the $\mathrm{pH}$ may decrease significantly with respect to that of the outer solution, whereas the $\mathrm{pSO}_{4}{ }^{2-}$ should reach very high values. Taking into account the diagrams shown in Fig. 3, the reaction of Eq. (10) would be displaced in the reverse sense. Hence, the $\mathrm{FeSO}_{4}{ }^{+}$ions entering the membrane would dissociate giving $\mathrm{Fe}^{3+}$ and $\mathrm{SO}_{4}{ }^{2-}$ ions as products. The former would cross the membrane, but the latter would migrate back to the central compartment. Fig. 8 shows a schematic representation of the dissociation of $\mathrm{FeSO}_{4}{ }^{+}$ ions taking place inside the CEM. This mechanism of exclusion of $\mathrm{SO}_{4}{ }^{2-}$ ions inside the CEM has a positive effect on the process of sulfuric acid recovery, since it impedes a greater decrease in the concentration of sulfates in the central compartment and allows the supply of more $\mathrm{SO}_{4}{ }^{2-}$ ions to the AEM. Moreover, these results are in agreement with our previous study, where the dissociation of sulfate complexes of $\operatorname{Cr}(\mathrm{III})$ and Fe(III) inside a CEM was proven by means of chronopotentiometric measurements [26].

\subsection{Current efficiency and specific energy consumption}

In order to evaluate the viability of the proposed configuration, the energy-related indicators of the ED cell have to be taken into account. For this purpose, the current efficiency $(\phi)$, which relates the current used for the passage of $\mathrm{SO}_{4}{ }^{2-}$ ions through the AEM to the total imposed current, was considered. The current efficiency for the transport of $\mathrm{SO}_{4}{ }^{2-}$ ions through the AEM is given by Eq. (25):

$$
\phi(t)=\frac{n \cdot F \cdot V \cdot(C(t)-C(0))}{\int_{0}^{t} I d t} \times 100
$$

where $n, F, V$ and $I$ are the number of equivalents per mole, the Faraday's constant, the volume of the anodic reservoir and the applied current, respectively. $C(0)$ and $C(t)$ represent the concentration of $\mathrm{SO}_{4}{ }^{2-}$ ions in the anodic compartment at the beginning of 
the experiments and at a specific time $t$, respectively. In addition, the specific energy consumption per each $\mathrm{kg}$ of $\mathrm{SO}_{4}{ }^{2-}$ ions recovered in the anolyte $\left(E_{s}\right)$ was also calculated using Eq.(26).

$E_{S}(t)=\frac{\int_{0}^{t} U_{C}(t) \cdot I d t}{3600 \cdot M \cdot V \cdot(C(t)-C(0))}$

$U_{C}$ represents the cell voltage measured between anode and cathode and $M$ the molecular weight of the $\mathrm{SO}_{4}{ }^{2-}$ ions.

The evolution of the current efficiency with time is presented in Fig. 9. $\phi$ values oscillate around $60 \%$ and remained almost constant during the ED process for all the applied currents. This implies that more than half of the imposed current density was employed to transfer $\mathrm{SO}_{4}{ }^{2-}$ ions through the AEM and, this current was thus effectively used to recover the sulfuric acid. Moreover, there is no substantial difference associated with the changes in the applied current, which seems to indicate that $\mathrm{SO}_{4}{ }^{2-}$ ions are effectively transported through the membrane at both the underlimiting and overlimiting range of currents. The slow decrease in the concentration of sulfates in the central reservoir ensures a constant supply of ions to the membrane surface and, was probably the reason for the constant evolution of $\phi$ values during the course of the ED process. Moreover, as indicated above, the mechanism by which the $\mathrm{FeSO}_{4}{ }^{+}$ions dissociate when reaching the membrane phase and release free $\mathrm{SO}_{4}{ }^{2-}$ ions toward the central compartment contributes to these results. The current which is not associated with the transport of $\mathrm{SO}_{4}{ }^{2-}$ ions through the AEM could be related to energy losses, the transport of other ions (such as $\mathrm{OH}^{-}$ions), the proton leakage through the AEM or due to the presence of non-conducting regions in the membrane $[28,29]$.

The results of current efficiency of Fig. 9 are similar to those obtained by Huang et al. [29], where a maximum in current efficiency for the recovery of sulfuric acid was achieved at intermediate current densities. The decrease in $\phi$ at low current densities was attributed to the predominant role of the water transport through the membrane. The magnitude of the water transport with respect to the migration of $\mathrm{SO}_{4}{ }^{2-}$ ions probably diminishes with the increase in current. In addition to this effect, the supply of ions 
toward the membrane surface can also be improved at overlimiting currents due to the generation of hydrodynamic instabilities in the diffusion boundary layer [30]. Finally, when the current exceeds significantly the $i_{\text {lim }}$ value $\left(15 \mathrm{~mA} \cdot \mathrm{cm}^{-2}\right)$, the scarcity of counter-ions in the diluting membrane/solution interface becomes more severe and the phenomenon of water splitting may be intensified.

The evolution of $E_{S}$ with time is shown in Fig. 10. $E_{S}$ was almost constant with time for all the applied currents. However, there is a notorious difference based on the applied current. The increase in the values of $E_{S}$ is moderate when increasing from 5 to $10 \mathrm{~mA} \cdot \mathrm{cm}^{-2}$, which can be originated by concentration polarization effects related to surpassing the $i_{\text {lim }}$ of the AEM. The high volume ratio (4:1) between the volumes of the central and side reservoirs may impede a drastic decrease in the conductivity of the depleting compartment. Therefore, this parameter plays a significant role, because it implied very slight changes in the cell voltage during the course of the experiments.

On the contrary, under an imposed current of $15 \mathrm{~mA} \cdot \mathrm{cm}^{-2}$, the specific energy consumption increased drastically to values around $20 \mathrm{~kW} \cdot \mathrm{h} \cdot \mathrm{kg}^{-1}$. As mentioned previously, precipitates of iron were observed at the anodic surface of the CEM at the end of this experiment. The final state of the membranes is shown in Fig. 11, where red precipitates are clearly observed on the effective area of the cationic membrane. The applied current density of $15 \mathrm{~mA} \cdot \mathrm{cm}^{-2}$ is very close to the $i_{\lim }$ of the CEM. Therefore, the $\mathrm{i}_{\lim }$ of the CEM was probably decreasing as the depletion of ions occurred in the central compartment until it reached, at a certain time, the value of $15 \mathrm{~mA} \cdot \mathrm{cm}^{-2}$. After reaching this value, the formation of precipitates could have started, hence increasing the voltage drop associated with the CEM. In addition to these results, it has to be noted that the limits of cell voltage of the power supply were reached after the $5 \mathrm{~h}$ of operation, which impeded conducting the experiment under galvanostatic conditions during the rest of the experiment. We can therefore conclude that the processes taking place near the CEM could limit the overall performance of the ED operation by increasing the energy consumption in the cell, even though obtaining remarkable rates of recovery of sulfuric acid. In this regard, the characteristics of the CEM should be carefully studied when optimizing the operating conditions for the treatment of AMD by ED. On the other hand, the anionic membrane was not damaged despite the fact that 
the applied current density exceeded considerably the $i_{\text {lim }}$ corresponding to this membrane (see Fig. 11(b)). 


\section{Conclusions}

The obtained results have proven that the recovery of sulfuric acid from AMD can be achieved by means of an ED cell. Significant increases in the sulfuric acid concentration were obtained with the proposed scheme consisting of a three-compartment ED cell with CEM and AEM. Moreover, the removal of Fe(III) ions from AMD can be performed simultaneously.

The determination of the concentration of sulfates and iron in the different compartments, together with the consideration of the speciation diagrams of mixtures of ferric and sodium sulfates allowed us to identify the phenomenon that ensures the recovery of sulfuric acid free of Fe(III) impurities. This phenomenon consists in the dissociation of complex ionic species occurring inside the internal phase of the membranes. Specifically, the high $\mathrm{pH}$ values prevailing inside the gel phase of the AEM promote the dissociation of the $\mathrm{Fe}\left(\mathrm{SO}_{4}\right)_{2}{ }^{-}$ions into $\mathrm{Fe}^{3+}$ and $\mathrm{SO}_{4}{ }^{2-}$ ions, being the former expelled back to the central compartment. In the case of the CEM, the co-ion exclusion mechanism inside the membrane phase leads to $\mathrm{pH}$ values lower and $\mathrm{pSO}_{4}{ }^{2-}$ values higher than in the outer solution. This change promotes the dissociation of $\mathrm{FeSO}_{4}{ }^{+}$ions. The resulting $\mathrm{SO}_{4}{ }^{2-}$ ions return back to the central compartment and can be transported subsequently through the AEM.

The energy efficiency of the sulfate transport through the AEM has been evaluated by means of calculating the $\phi$ and $E_{S}$ values, and the stationarity of both indicators is evidence of the reliability of the process. The volume ratio between the different compartments of the ED cell exerts a key role in the energy consumed during the treatment of AMD. The increase in the applied current density led to an increase in the concentrating ratio of sulfuric acid, which reached the value of 4.00 for $15 \mathrm{~mA} \cdot \mathrm{cm}^{-2}$. However, the increase in the concentrating ratio was not proportional to the increments in current density. This may be explained by the increased dissociation of water in the AEM when its $\mathrm{i}_{\text {lim }}$ value is surpassed and the subsequent transport of $\mathrm{OH}^{-}$ions through the AEM. In addition, the dissociation of $\mathrm{HSO}_{4}{ }^{-}$ions in the AEM and the involvement of the $\mathrm{SO}_{4}{ }^{2-}$ ions crossing the AEM in hydrolysis reactions in the anodic compartment contribute also to this effect. Finally, the formation of precipitates on the CEM is a 
phenomenon to be prevented because it increases the cell voltage, thus increasing the energy requirements for the process. 


\section{Acknowledgements}

This work was supported by Ministerio de Economía y Competitividad (Spain) with the project number CTQ2012-37450-C02-01/PPQ. M.C. Martí-Calatayud is grateful to the Universitat Politècnica de València for a postgraduate grant (Ref.: 2010-12). D.C. Buzzi wants to express her gratitude to CAPES (Brazil) for a postgraduate grant (Proc. BEX 8747/11-3). 


\section{References}

[1] P. Sobron, F. Rull, F. Sobron, A. Sanz, J. Medina, C. J. Nielsen, Raman spectroscopy of the system iron(III)-sulfuric acid-water: An approach to Tinto River's (Spain) hydrogeochemistry, Spectrochim. Acta, Part A, 68 (2007) 11381142.

[2] Jennings, S. R., Neuman, D. R., Blicker, P. S. Acid mine drainage and effects on fish health and ecology: a review. Reclamation Research Group Publication. 2008.

[3] J. M. Nieto, A. M. Sarmiento, M. Olías, C. R. Canovas, I. Riba, J. Kalman, T. A. Delvalls, Acid mine drainage pollution in the Tinto and Odiel rivers (Iberian Pyrite Belt, SW Spain) and bioavailability of the transported metals to the Huelva Estuary, Environ. Int., 33 (2007) 445-455.

[4] M. C. Martí-Calatayud, M. García-Gabaldón, V. Pérez-Herranz, E. Ortega, Determination of transport properties of Ni(II) through a Nafion cation-exchange membrane in chromic acid solutions, J. Membr. Sci., 379 (2011) 449-458.

[5] Y. Oztekin, Z. Yazicigil, Recovery of acids from salt forms of sodium using cation-exchange membranes, Desalination, 212 (2007), 62-69.

[6] Treatment of Acid Mine Drainage. House of Commons Library. 1999. London.

[7] R. Ibanez, D. F. Stamatialis, M. Wessling, Role of membrane surface in concentration polarization at cation exchange membranes, J. Membr. Sci., 239 (2004) 119-128.

[8] S. Cattoir, D. Smets, A. Rahier, The use of electro-electrodialysis for the removal of sulphuric acid from decontamination effluents, Desalination, 121 (1999) 123130.

[9] L. Cifuentes, I. García, R. Ortiz, J.M. Casas, The use of electrohydrolysis for the recovery of sulphuric acid from copper-containing solutions, Sep. Purif. Technol., 50 (2006) 167-174. 
[10] J. Wisniewski, G. Wisniewska, T. Winnicki, Application of bipolar electrodialysis to the recovery of acids and bases from water solutions, Desalination, 169 (2004) 11-20.

[11] D. C. Buzzi, L. S. Viegas, M. A. S. Rodrigues, A. M. Bernardes, J. A. S. Tenório, Water recovery from acid mine drainage by electrodialysis, Miner. Eng., 40 (2013) 82-89.

[12] S. Kotrlý, L. Sucha, Handbook of Chemical Equilibria in Analytical Chemistry, Ellis Horwood Ltd., Chinchester, 1985.

[13] M. C. Martí-Calatayud, M. García-Gabaldón, V. Pérez-Herranz, S. Sales, S. Mestre, Synthesis and electrochemical behavior of ceramic cation-exchange membranes based on zirconium phosphate, Ceram. Int., 39 (2013) 4045-4054.

[14] N. Pismenskaya, E. Laktionov, V. Nikonenko, A. El Attar, B. Auclair, G. Pourcelly, Dependence of composition of anion-exchange membranes and their electrical conductivity on concentration of sodium salts of carbonic and phosphoric acids, J. Membr. Sci. 181 (2001) 185-197.

[15] N. Pismenskaya, V. Nikonenko, E. Volodina, G. Pourcelly, Electrotransport of weak-acid anions through anion-exchange membranes, Desalination, 147 (2002) 345-350.

[16] N.D. Pismenskaya, E.I. Belova, V.V. Nikonenko, C. Larchet, Electrical conductivity of cation- and anion-exchange membranes in ampholyte solutions, Russ. J. Electrochem., 44 (2008) 1285-1291.

[17] Y. Lorrain, G. Pourcelly, C. Gavach, Transport mechanism of sulfuric acid through an anion exchange membrane, Desalination, 109 (1997) 231-239.

[18] G. Pourcelly, I. Tugas, C. Gavach, Electrotransport of sulphuric acid in special anion exchange membranes for the recovery of acids, J. Membr. Sci., 97 (1994) 99-107.

[19] X.T. Le, Contribution to the study of properties of Selemion AMV anion exchange membranes in acidic media, Electrochim. Acta, 108 (2013) 232-240. 
[20] V.A. Shaposhnik, V.I. Vasil'eva, O.V. Grigorchuk, The interferometric investigations of electromembrane processes, Adv. Colloid Interface Sci., 139 (2008) 74-82.

[21] Y. Lorrain, G. Pourcelly, C. Gavach, Influence of cations on the proton leakage through anion-exchange membranes, J. Membr. Sci., 110 (1996) 181-190.

[22] E.I. Belova, G.Y. Lopatkova, N.D. Pismenskaya, V.V. Nikonenko, C. Larchet, G. Pourcelly, Effect of anion-exchange membrane surface properties on mechanisms of overlimiting mass transfer, J. Phys. Chem. B, 110 (2006) 13458-13469.

[23] T.C. Huang, R.S. Juang, Recovery of sulfuric acid with multicompartment electrodialysis, Ind. Eng. Chem. Process Des. Dev., 25 (1986) 537-542.

[24] M. García-Gabaldón, V. Pérez-Herranz, J. García-Antón, J. L. Guiñón, Electrochemical recovery of tin from the activating solutions of the electroless plating of polymers: Galvanostatic operation, Sep. Purif. Technol., 51 (2006) 143149.

[25] A. M. Peers, Membrane phenomena, Discuss. Faraday Soc., 24 (1956) 124-125.

[26] M. C. Martí-Calatayud, M. García-Gabaldón, V. Pérez-Herranz, Effect of the equilibria of multivalent metal sulfates on the transport through cation-exchange membranes at different current regimes, J. Membr. Sci., 443 (2013) 181-192.

[27] C. Casademont, M. A. Farias, G. Pourcelly, L. Bazinet, Impact of electrodialytic parameters on cation migration kinetics and fouling nature of ion-exchange membranes during treatment of solutions with different magnesium/calcium ratios, J. Membr. Sci., 325 (2008) 570-579.

[28] J. Jörissen, S. M. Breiter, C. Funk, Ion transport in anion exchange membranes in presence of multivalent anions like sulfate or phosphate, J. Membr. Sci., 213 (2003) 247-261.

[29] J. H. Choi, S. H. Kim, S. H. Moon, Heterogeneity of Ion-Exchange Membranes: The Effects of Membrane Heterogeneity on Transport Properties, J. Colloid Interface Sci., 241 (2001) 120-126. 
[30] M.C. Martí-Calatayud, M. García-Gabaldón, V. Pérez-Herranz, Study of the effects of the applied current regime and the concentration of chromic acid on the transport of $\mathrm{Ni}^{2+}$ ions through Nafion 117 membranes, J. Membr. Sci., 392-393 (2012) 137-149. 


\section{LIST OF TABLES.}

Table 1. Composition of the original source of AMD and the synthetic solutions used in the ED experiments.

Table 2. Concentration in mol. $\mathrm{L}^{-1}$ of the species present in mixtures of $0.02 \mathrm{M} \mathrm{Fe}_{2}\left(\mathrm{SO}_{4}\right)_{3}$ and $0.01 \mathrm{M} \mathrm{Na}_{2} \mathrm{SO}_{4}$ in equilibrium conditions. 


\section{LIST OF FIGURES.}

Fig. 1. Configuration of the ED cell used in the experiments for the recovery of sulfuric acid from AMD solutions.

Fig. 2. Speciation diagram of $\mathrm{SO}_{4}{ }^{2-}$ species as a function of $\mathrm{pH}$. (The vertical dashed line represents the initial equilibrium conditions).

Fig. 3. Speciation diagram of Fe(III) species (a) as a function of $\mathrm{pH}$ and (b) as a function of $\mathrm{pSO}_{4}{ }^{2-}$. (The vertical dashed lines represent the initial equilibrium conditions)

Fig. 4. Evolution with time of the concentration of $\mathrm{SO}_{4}{ }^{2-}$ ions in the anodic and central compartments for the different applied current densities.

Fig. 5. Dissociation of $\mathrm{Fe}\left(\mathrm{SO}_{4}\right)_{2}{ }^{-}$ions in the interstitial solution of an AEM originated by the Donnan exclusion of $\mathrm{H}^{+}$ions and the increased $\mathrm{pH}$ inside the membrane gel phase.

Fig. 6. (a) Effect of the applied current density on the increase in the acidity of the anodic compartment. (b) Evolution of $\mathrm{pH}$ in the different compartments of the ED cell during the experiment conducted at $10 \mathrm{~mA} \cdot \mathrm{cm}^{-2}$.

Fig. 7. Evolution with time of the concentration of iron in the cathodic compartment for different applied current densities.

Fig. 8. Mechanism of dissociation of $\mathrm{FeSO}_{4}{ }^{+}$ions inside a $\mathrm{CEM}$ as a consequence of the low $\mathrm{pH}$ value in the membrane gel phase if compared with that of the outer solution.

Fig. 9. Evolution of the current efficiency for the passage of $\mathrm{SO}_{4}{ }^{2-}$ ions through the AEM under the imposition of different values of current density.

Fig. 10. Evolution of the specific energy consumption for the passage of $\mathrm{SO}_{4}{ }^{2-}$ ions through the AEM under the imposition of different values of current density.

Fig. 11. Pictures of the ion-exchange membranes obtained after the experiment conducted with the imposition of a current density of $15 \mathrm{~mA} \cdot \mathrm{cm}^{-2}$. (a) HDX 100 CEM and (b) HDX 200 AEM. 
Table 1. Composition of the original source of AMD and the synthetic solutions used in the ED experiments.

\begin{tabular}{ccccc} 
Solution & $\mathbf{F e}(\mathbf{I I I})\left(\mathbf{m o l} \cdot \mathbf{L}^{-1}\right)$ & $\mathbf{N a}(\mathbf{I})\left(\mathbf{m o l} \cdot \mathbf{L}^{-\mathbf{1}}\right)$ & $\mathbf{S O}_{4}{ }^{2-}\left(\mathbf{m o l} \cdot \mathbf{L}^{-1}\right)$ & $\mathbf{p H}$ \\
\hline AMD source & 0.037 & 0.017 & 0.082 & 2.48 \\
$\begin{array}{c}\text { Synthetic solution: } \\
0.02 \mathrm{M} \mathrm{Fe}_{2}\left(\mathrm{SO}_{4}\right)_{3}+\end{array}$ & 0.040 & 0.020 & 0.070 & 1.68 \\
$0.01 \mathrm{M} \mathrm{Na}_{2} \mathrm{SO}_{4}$ & & & &
\end{tabular}


Table 2. Concentration in $\mathrm{mol} \cdot \mathrm{L}^{-1}$ of the species present in mixtures of $0.02 \mathrm{M} \mathrm{Fe}_{2}\left(\mathrm{SO}_{4}\right)_{3}$ and $0.01 \mathrm{M} \mathrm{Na}_{2} \mathrm{SO}_{4}$ in equilibrium conditions.

\begin{tabular}{cccccccccc}
$\mathrm{pH}$ & $\mathrm{Fe}^{3+}$ & $\mathrm{FeSO}_{4}{ }^{+}$ & $\mathrm{Fe}\left(\mathrm{SO}_{4}\right)_{2}{ }_{2}^{-}$ & $\mathrm{FeOH}^{2+}$ & $\mathrm{Fe}(\mathrm{OH})_{2}{ }^{+}$ & $\mathrm{Na}^{+}$ & $\mathrm{NaSO}_{4}{ }^{-}$ & $\mathrm{SO}_{4}{ }^{2-}$ & $\mathrm{HSO}_{4}{ }^{-}$ \\
\hline 1.68 & $3.90 \times 10^{-4}$ & $3.37 \times 10^{-2}$ & $5.80 \times 10^{-3}$ & $1.21 \times 10^{-4}$ & $1.78 \times 10^{-6}$ & $1.92 \times 10^{-2}$ & $7.59 \times 10^{-4}$ & $7.87 \times 10^{-3}$ & $1.61 \times 10^{-2}$
\end{tabular}




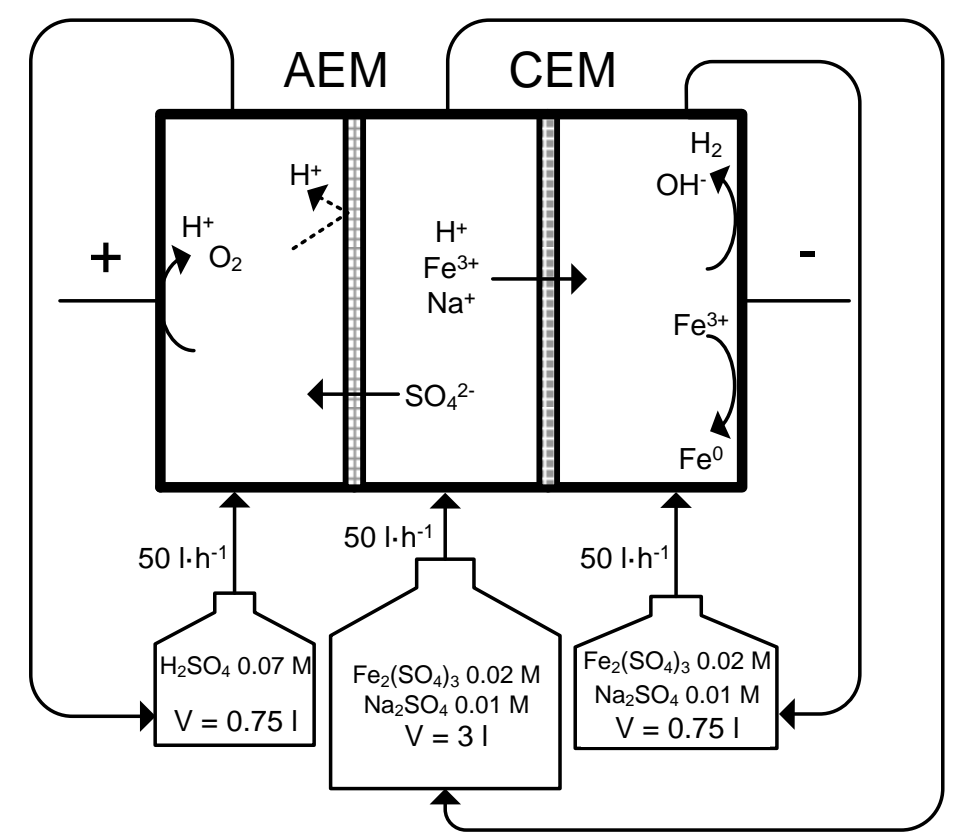

Fig. 1. Configuration of the ED cell used in the experiments for the recovery of sulfuric acid from AMD solutions. 


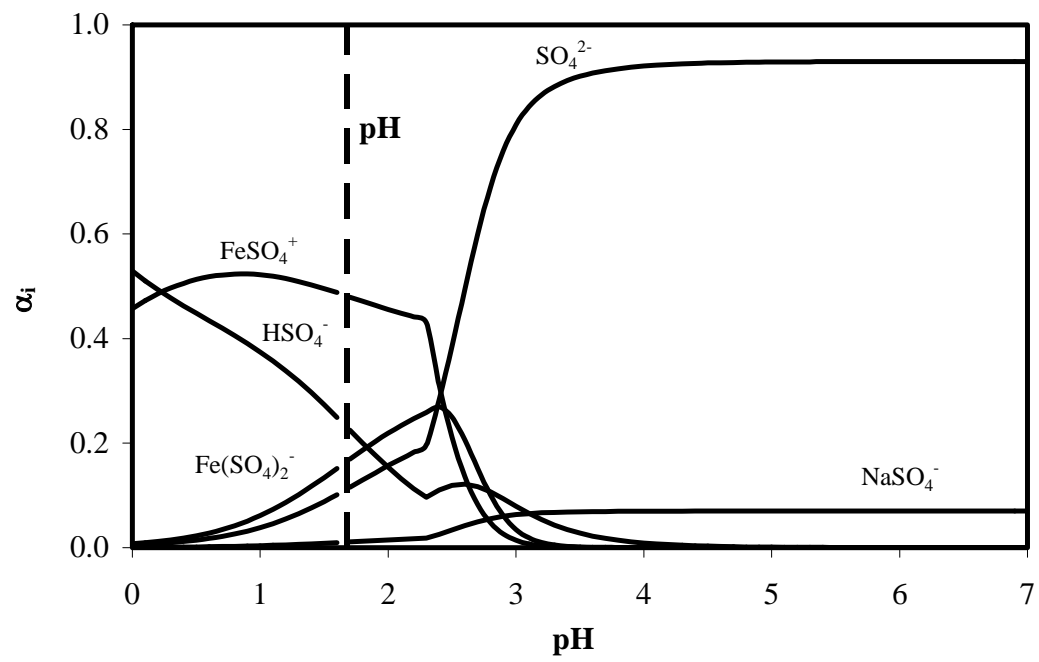

Fig. 2. Speciation diagram of $\mathrm{SO}_{4}{ }^{2-}$ species as a function of $\mathrm{pH}$. (The vertical dashed line represents the initial equilibrium conditions). 
a)

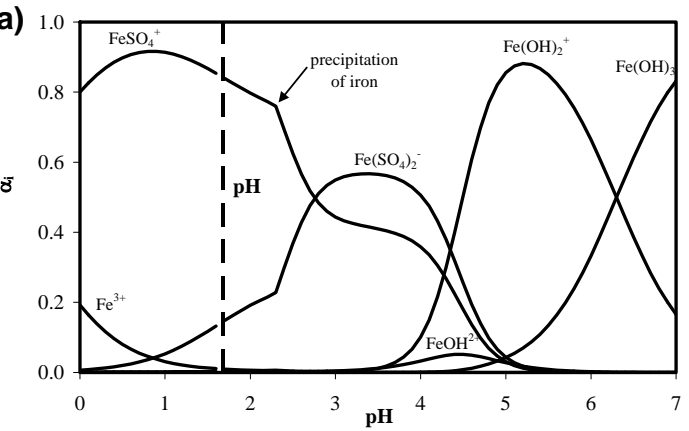

b)

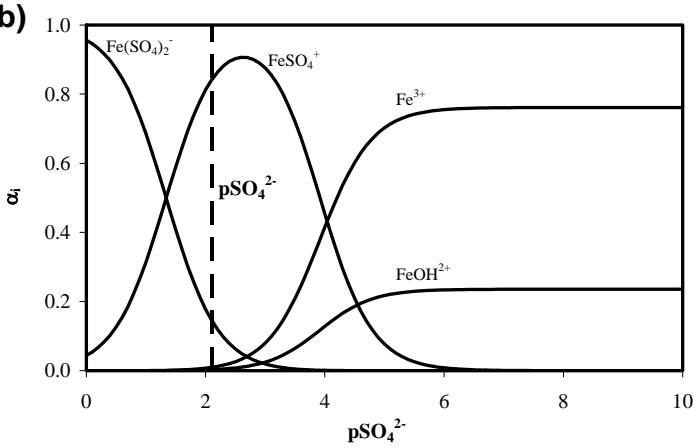

Fig. 3. Speciation diagram of Fe(III) species (a) as a function of $\mathrm{pH}$ and (b) as a function of $\mathrm{pSO}_{4}{ }^{2-}$. (The vertical dashed lines represent the initial equilibrium conditions) 


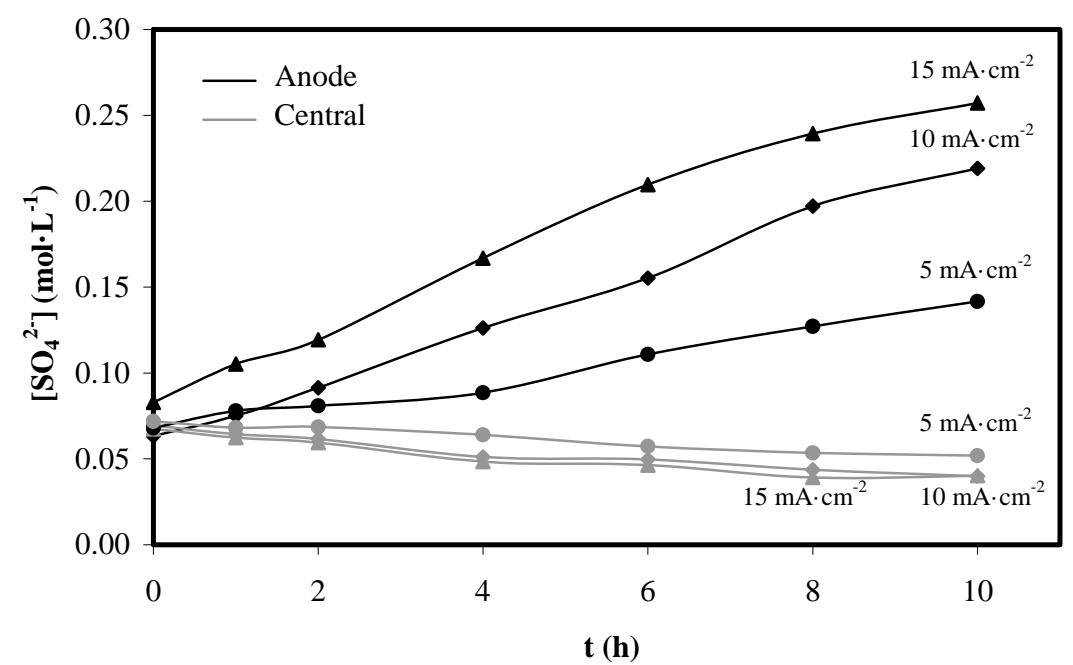

Fig. 4. Evolution with time of the concentration of $\mathrm{SO}_{4}{ }^{2-}$ ions in the anodic and central compartments for the different applied current densities. 


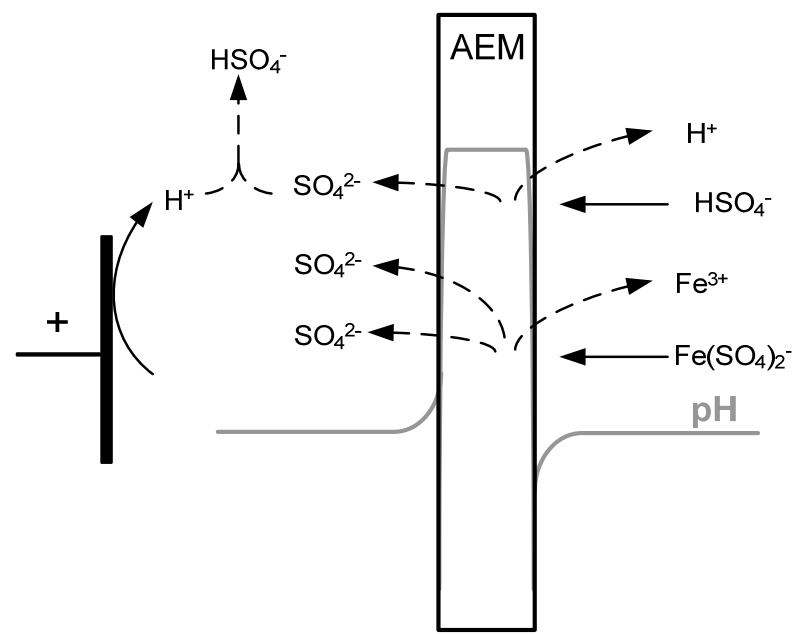

Fig. 5. Dissociation of $\mathrm{Fe}\left(\mathrm{SO}_{4}\right)_{2}{ }^{-}$ions in the interstitial solution of an AEM originated by the Donnan exclusion of $\mathrm{H}^{+}$ions and the increased $\mathrm{pH}$ inside the membrane gel phase. 

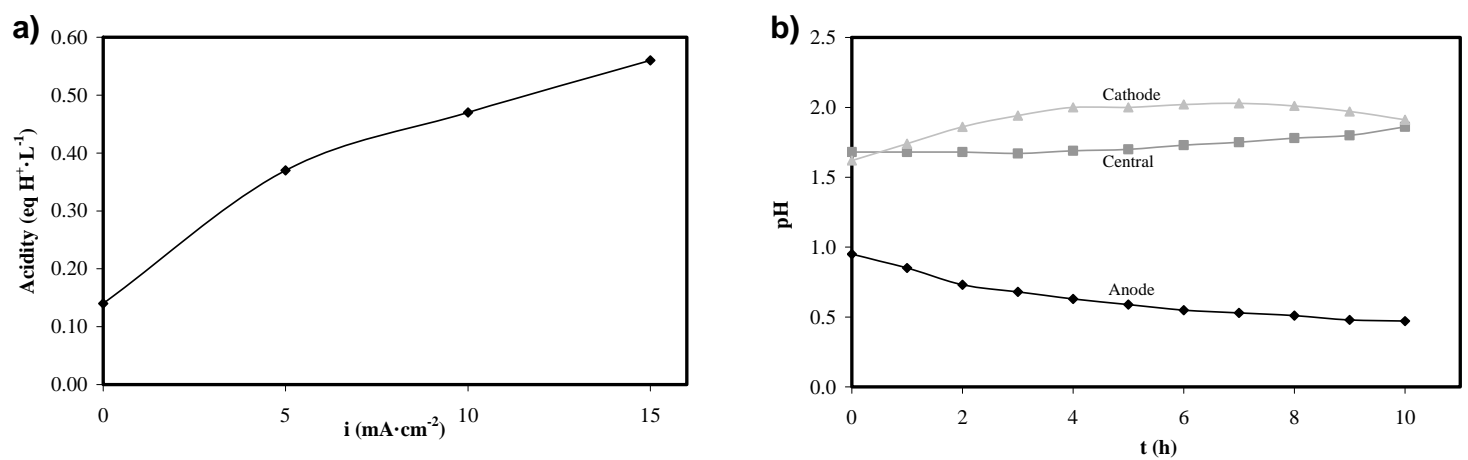

Fig. 6. (a) Effect of the applied current density on the increase in the acidity of the anodic compartment. (b) Evolution of $\mathrm{pH}$ in the different compartments of the ED cell during the experiment conducted at $10 \mathrm{~mA} \cdot \mathrm{cm}^{-2}$. 


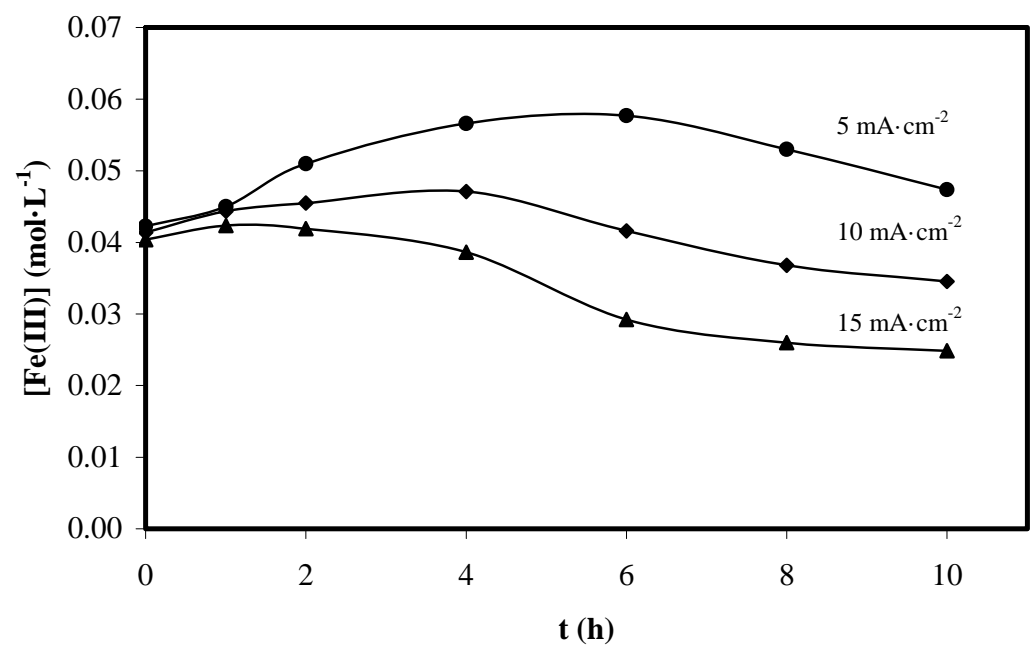

Fig. 7. Evolution with time of the concentration of iron in the cathodic compartment for different applied current densities. 


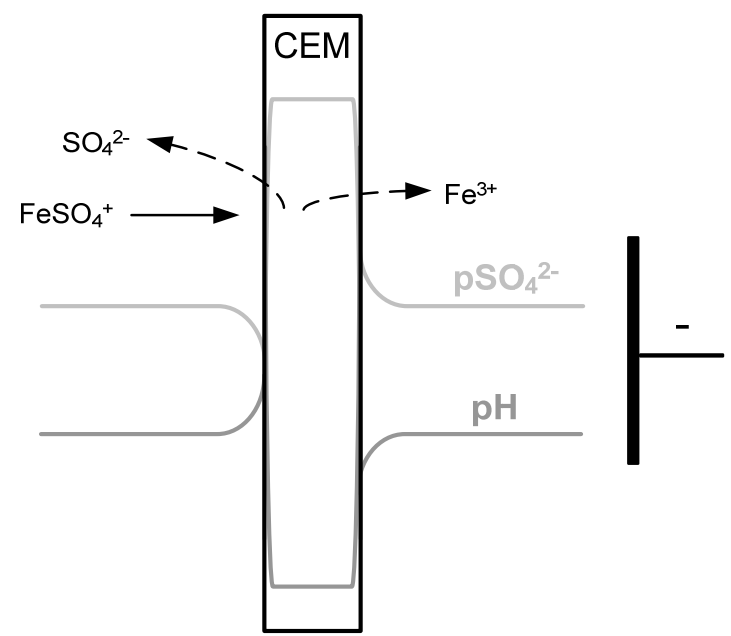

Fig. 8. Mechanism of dissociation of $\mathrm{FeSO}_{4}{ }^{+}$ions inside a $\mathrm{CEM}$ as a consequence of the low $\mathrm{pH}$ value in the membrane gel phase if compared with that of the outer solution. 


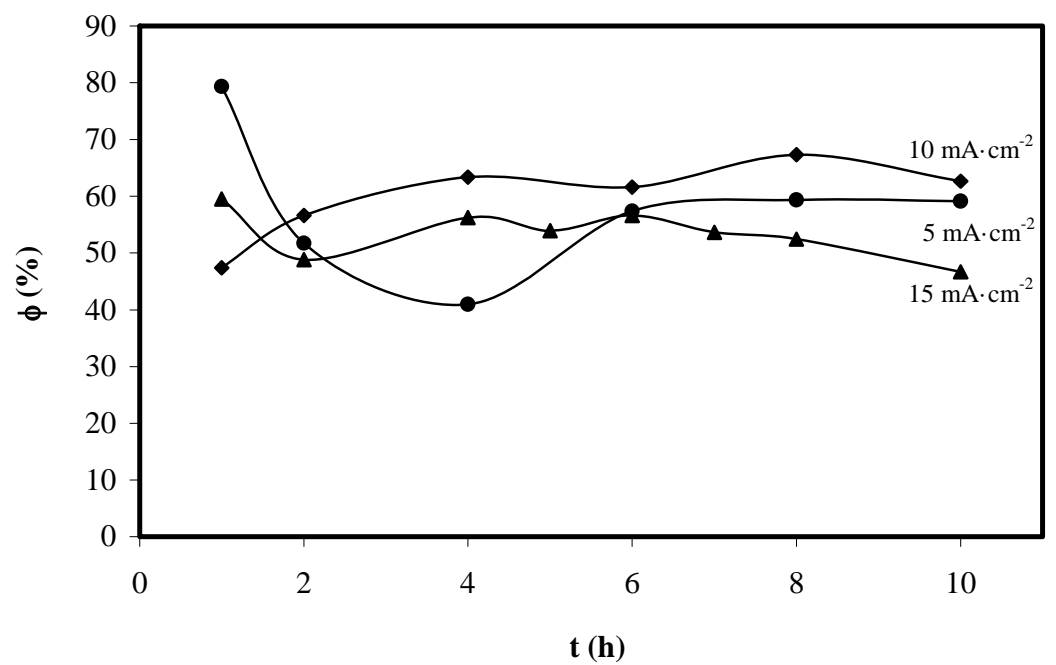

Fig. 9. Evolution of the current efficiency for the passage of $\mathrm{SO}_{4}{ }^{2-}$ ions through the AEM under the imposition of different values of current density. 


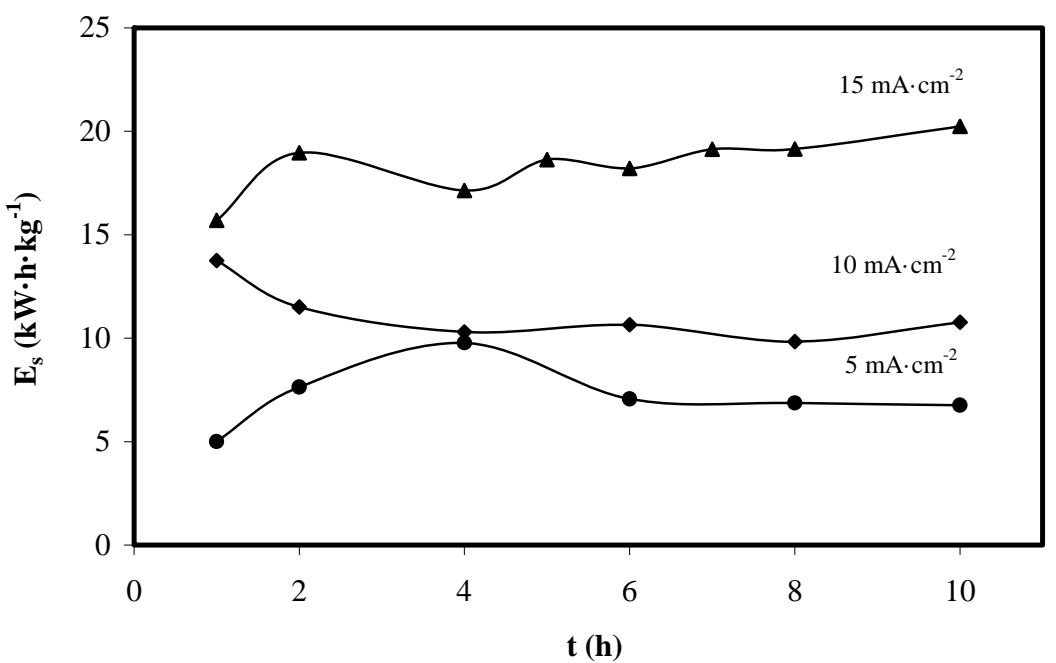

Fig. 10. Evolution of the specific energy consumption for the passage of $\mathrm{SO}_{4}{ }^{2-}$ ions through the AEM under the imposition of different values of current density. 
a)

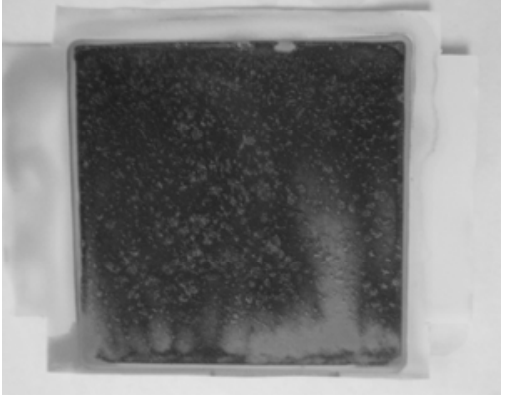

b)

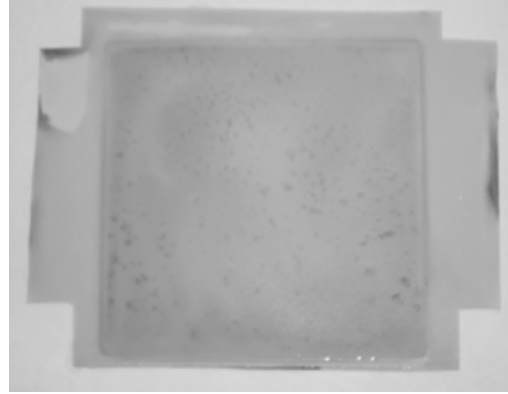

(b)

Fig. 11. Pictures of the ion-exchange membranes obtained after the experiment conducted with the imposition of a current density of $15 \mathrm{~mA} \cdot \mathrm{cm}^{-2}$. (a) HDX 100 CEM and (b) HDX 200 AEM. 